\section{The Sanctity of Life Doctrine in Medicine: a Critique}

Helga Kuhse, 235 pages, Oxford, £25, Clarendon Press, 1987

This book is a study of the ethics of homicide in medical practice almost wholly devoted to showing the inadequacy, because of its inconsistency, of a sanctity of life approach to that ethics. According to the first chapter, the sanctity of life approach is based on the notion that the direct taking of innocent life in medical practice, as elsewhere, is absolutely forbidden. But other important ideas are seen to be associated with the sanctity of life principle as discussion proceeds: for example that there is something inherently valuable in human life independent of the quality of life it occasions, that all human life is of equal value, that there is something inherently wrong in the taking of human life as such. To the sanctity of life approach with these implications the author opposes an account of the ethics of homicide based on a quality of life approach. This uses the notion that life is valuable only in so far as it is a precondition of other things (for example pleasure or the exercise of autonomy). Homicide is only an evil if it forecloses a life which is associated with these other goods.

Three lengthy chapters in the middle of the book, amounting to some threequarters of its material, treat of the ways in which defenders of the sanctity of life principle try to reconcile their views with the fact that many apparently licit clinical decisions have among their foreseen consequences that a life should not be prolonged as long as is medically possible or that a patient's death should be hastened. Acts and omissions, the principle of double effect, and extraordinary and ordinary means are treated here. The critique of these devices is thorough and penetrating but its general outline is familiar from other treatments of homicide and medical ethics provided by quality of life theorists (including the author's own work with Singer on life/death decisions in paediatrics). The general conclusion reached is that these devices are used with notable inconsistency by their proponents and do not offer any good grounds for supposing that if the hastening of death (or the failure to prolong life) are foreseen consequences of voluntary actions, these acts should not be considered homicidal in their intent and thrust. Sanctity of life theorists, in other words, are using a much broader notion of justified homicide than they suppose and are in effect endorsing the belief that quality of life considerations can justify an act homicidal in its thrust.

The principle of double effect is the most important of the devices used in the ethics the author opposes. Her treatment of it is polemical in character. A more independent discussion is perhaps needed to settle finally the question of whether the fact that a homicidal consequence is no part of the reason for an act being performed does at all imply that this consequence is (as Thomists argue) no part of the act itself, but a mere circumstance which bears less centrally on its moral character. Overall, however, it must be said that the author succeeds in showing that we need a broader notion of justified homicide than that suggested by traditional talk of the sanctity of life.

What does not follow from the force of the central critical chapters of this book is the truth of the quality of life ethics of homicide expounded in the final chapter. For the quality of life and sanctity of life accounts of the ethics of homicide are not exhaustive alternatives, and as a study of the applied ethics of homicide this book is seriously deficient in implying that they are. It is possible to hold that human life is intrinsically a good (and homicide therefore intrinsically an evil) while recognising that in some cases the consequences of continued living (for example in great pain in a terminal state) justify or mitigate the taking of life. The intrinsic wrong or evil of homicide is not an absolute wrong or evil, though homicide is always a drastic act which unless justified or mitigated is wrong without qualification.

To say that homicidal acts are intrinsically wrong, and forbiddew unless justified, is to endorse the ides that there is something about being human which makes a life importantly valuable. In her last chapter the author seeks to overthrow this impediment to her quality of life view by appealing to the manifest injustices of speciesism. Like others before her she is unable to distinguish between saying that being a human life is necessary for having a peculiar value and saying that it is sufficient. Let us hope that the latter view is defensible, for then we shall avoid the miserable conclusion endorsed in this work to the effect that there are no direct reasons why it is wrong to kill human infants.

PETER BYRNE

Lecturer in the Philosophy of Religion and $a$ Director of the Centre of Medical Law and Ethics, King's College, London

\section{Persons and Personality}

Edited by Arthur Peacocke and Grant Gillett, 222 pages, Oxford, £19.50, Basil Blackwell, 1987

The Ian Ramsey Centre in Oxford has become an important institute for the $\varrho$ study of philosophical and theological $\bar{\gamma}$ issues surrounding the practice of 